\title{
Global Photosynthesis is An Instrument in Large Natural Systems Studies
}

\author{
Ivlev AA $^{1 *}$ \\ aa.ivlev@list.ru \\ Received: January 16, 2020; Accepted: January 22, 2020; Published: February 06, 2020
}

${ }^{1}$ Russian State Agrarian University - Moscow Agricultural Academy of Timiryazev, Timiryazevskaya str.49, Moscow, Russia

${ }^{\star}$ Corresponding Author: Russian State Agrarian University - Moscow Agricultural Academy of Timiryazev, Timiryazevskaya str.49, Moscow 127550, Russia; E-mail:

\begin{abstract}
The approximation of photosynthesis equation to describe global photosynthesis is considered. It is shown that the main features of global photosynthesis can be divided into features similar to traditional photosynthesis and features associated with its participation in the global carbon cycle. The global photosynthesis is used to describe interactions of geological and biosphere processes.
\end{abstract}

Keywords: Carbon cycle, Ecological compensation point, Photosynthesis, Photosynthetic and heterotrophic Biomass, Lithospheric plates, Sedimentary organic matter, Sulfate reduction

Photosynthesis is usually considered in respect to individual organism. Its formal description can be given as follows:

$\mathrm{CO}_{2}+\mathrm{H}_{2} \mathrm{O} \stackrel{h v}{\rightarrow}\left(\mathrm{C} \mathrm{H}_{2} \mathrm{O}\right)+\mathrm{O}_{2}$

where $\mathrm{CO}_{2}$ and $\mathrm{H}_{2} \mathrm{O}$ are photosynthetic substrates taken from the environment, $\left(\mathrm{CH}_{2} \mathrm{O}\right)$ is analog of biomass and $\mathrm{O}_{2}$ are photosynthetic products. They are produced in parallel during photosynthesis. In the most of cases $\mathrm{CO}_{2}$ is a rate limiting factor of the reaction. Hence, one can consider photosynthesis as the 1-st order chemical reaction whose kinetics is well examined. It stems from this approximation that changes of $\mathrm{CO}_{2}$ concentration and that of $\mathrm{O}_{2}$ concentration should be antiphase (substrate - product link), whereas biomass growth and $\mathrm{O}_{2}$ concentration (product - product link) should display proportional changes. In large systems, such as the biosphere or the global carbon cycle, which include a large number of individual organisms, photosynthesis should be considered as some generalized characteristic of an ensemble of organisms, which is defined as global. The photosynthesis equation for global photosynthesis should look otherwise as compared with equation (1), since the term "biomass" should be defined differently. At the time, the notable Russian geochemist [1], who investigated interaction of geological and biosphere processes, introduced the concept of "living matter", defining it as the total biomass of all living organisms on the Earth. The term "living matter" as well as the "global photosynthesis" is a generalized characteristics. We used this term to describe global photosynthesis in the biosphere. As known, "living matter" consists of two parts: photosynthesized and heterotrophic biomass:

"living matter" $=$ biomass $_{\text {photosynthesized }}+$ biomass $_{\text {heterotrophic }}$

The "living matter" as a whole can be taken as a photosynthetic product consisting of the primary photosynthetic product, photosynthesized biomass, and the secondary photosynthetic product, heterotrophic biomass. When considering photosynthesis in the biosphere or in the other large system, it is evident the photosynthesis equation should look otherwise. In case of biosphere the equation should look like that:

$\left(\mathrm{CO}_{2}+\mathrm{H}_{2} \mathrm{O}\right)_{\text {atmosphere + hydrosphere }} \stackrel{h v}{\rightarrow}$ "living matter" $+\mathrm{O}_{2}$

Indeed, equation (3) reflects the fact that $\mathrm{CO}_{2}$ and $\mathrm{H}_{2} \mathrm{O}$ are taken from the natural "atmosphere - hydrosphere" system, while resultant oxygen is released into the atmosphere. Equation (3) can be regarded as the equation of global photosynthesis, since the oxygen, which is released into the atmosphere, includes both the oxygen, produced by primary photosynthesizing organisms, as well as the oxygen, produced by those photosynthesizing organisms, whose biomass had become a source of carbon for the consumers of food chains [2]. Let's see now, how the photosynthesis equation can be applied to the global carbon cycle. Given the above said and the key role of photosynthesis as well as that getting into the sediment, biomass turns into a sedimentary organic matter, the photosynthetic equation can be presented as follows:

$\left(\mathrm{CO}_{2}+\mathrm{H}_{2} \mathrm{O}\right)_{\text {atmosphere + hydrosphere }} \stackrel{h v}{\rightarrow}$ "living matter" $+\mathrm{C}_{\mathrm{OM}}+\mathrm{O}_{2}$ atmosphere

In equation (4) the biomass is presented by two parts. The first part is the biomass of currently living organisms. The corresponding portion of the oxygen released into the atmosphere. The second part of the biomass corresponds to the buried organic matter, which in the past was "living matter". Oxygen, which corresponds to this part of the biomass converted into sedimentary organic matter, was released in the photosynthesis reaction, when corresponding organisms were alive. This oxygen has accumulated in the atmosphere. The validity of using the photosynthesis equation for the global carbon 
cycle is confirmed by two correlations of natural parameters. The first corresponds to the "substrate - product" relationship stemmed from photosynthesis equation. One can see the expected counterphase correlation between time-averaged changes of $\mathrm{CO}_{2}$ and $\mathrm{O}_{2}$ concentrations in the atmosphere, obtained from model calculations in the Phanerozoic (Fig.1). The second correlation corresponds to the "product -product" relationship from photosynthesis equation (Fig.2)

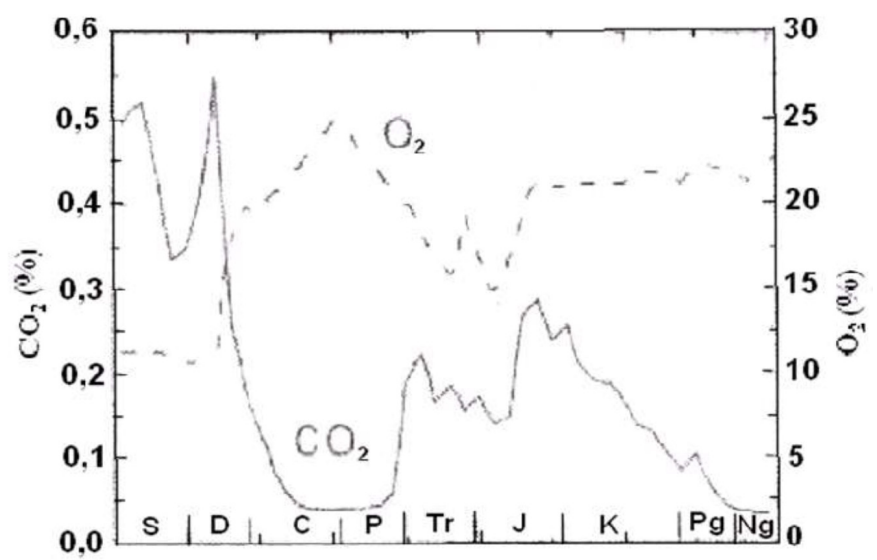

Figure 1. Changes in the atmospheric concentration of $\mathrm{CO}_{2}$ (solid line) and $\mathrm{O}_{2}$ (dashed line) during Phanerozoic eon. Abbreviation of the periods: S - Silurian, D - Devonian, $\mathrm{C}$ - Carboniferous, P- Permian (Palaeozoic era); Tr - Triassic, J - Jurassic, K - Cretaceous (Mesozoic era); $\mathrm{Pg}$ - Palaeogene and $\mathrm{Ng}$ - Neogene (Cenozoic era). Given that the reaction is of the first order, one can expect an antiphase link between $\mathrm{CO}_{2}$ and $\mathrm{O}_{2}$. The first two periods of Palaeozoic era (Cambrian and Ordovician) are not shown because there is some uncertainty around establishing the $\mathrm{CO}_{2}$ and $\mathrm{O}_{2}$ concentrations. $\mathrm{CO}_{2}$ estimates are from the Geocarb III model (Igamberdiev, Lea, 2006).

One can see the expected syn-phase correlation between oxygen growth in the atmosphere and the increase in the mass of buried carbon (mol/million years) in the same time interval. Moreover, one can conclude that it is possible to neglect the biomass that corresponds to "living matter" as compared with buried organic matter. Following this approximation, the equation of photosynthesis for global carbon cycle can be simplified like that:

$\left(\mathrm{CO}_{2}+\mathrm{H}_{2} \mathrm{O}\right)_{\text {atmosphere+hydrosphere }} \stackrel{h v}{\rightarrow} \mathrm{C}_{\mathrm{OM}}+\mathrm{O}_{2 \text { атмосфера }}$

To use the term "global photosynthesis" in carbon cycle studies effectively, it is important to understand what properties of traditional photosynthesis could be applied to the global photosynthesis, according its definition [3]. The most important property is the presence of two reciprocally related processes - assimilation of $\mathrm{CO}_{2}$ and photorespiration. Besides, an increase in the concentration of $\mathrm{CO}_{2}$ in the environment strengthens the assimilation function, while an increase in the concentration of $\mathrm{O}_{2}$ in the atmosphere increases photorespiration. Therefore the $\mathrm{CO}_{2} / \mathrm{O}_{2}$ ratio is the important characteristic of the global carbon cycle. The growth of this ratio in the atmosphere causes sedimentary organic matter accumulation in the earth's crust. In periods when the ratio drops, the organic matter content in the crust decreases. Like traditional photosynthesis, global photosynthesis is accompanied by isotopic fractionation. Notably $\mathrm{CO}_{2}$ assimilation and photorespiration are accompanied by the effects of the opposite sign. Increased $\mathrm{CO}_{2}$ assimilation (due to $\mathrm{CO}_{2}$
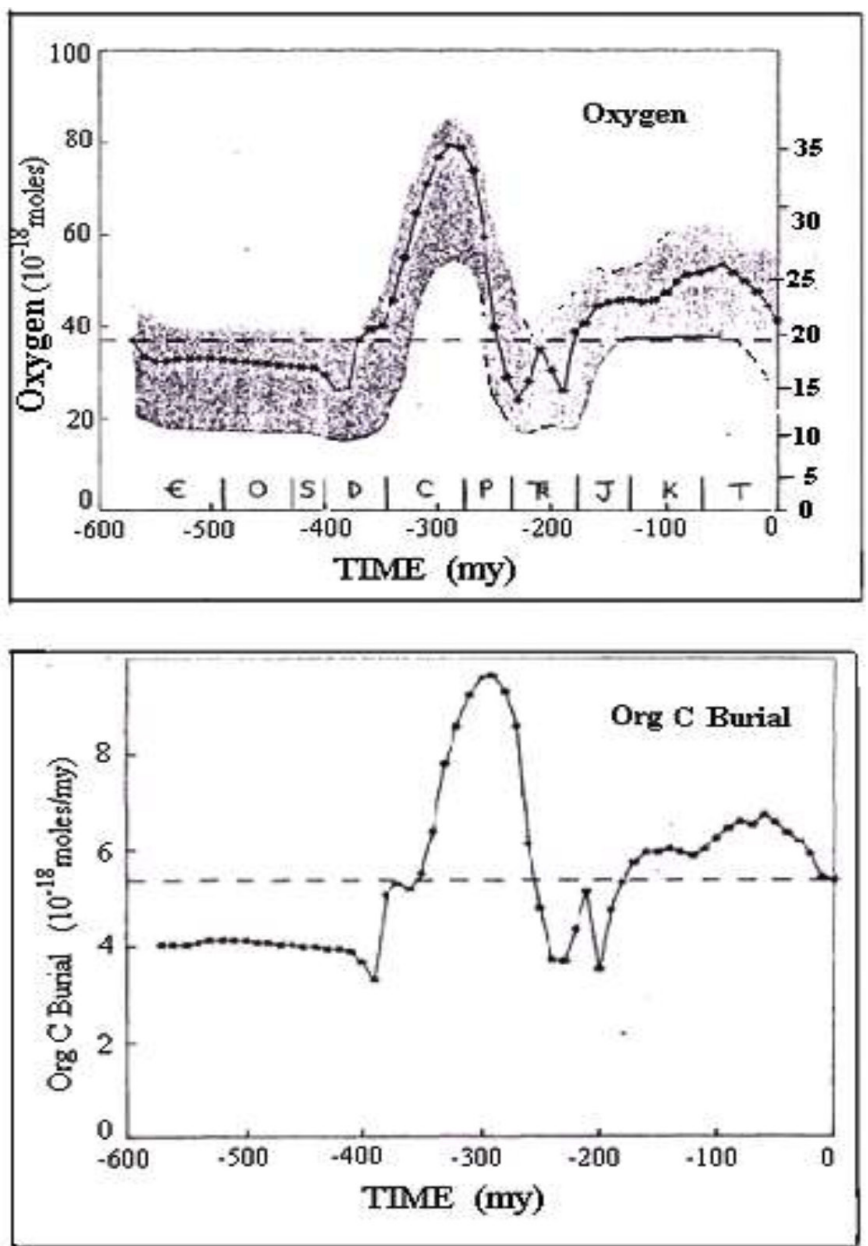

Figure 2. The in-phase changes of oxygen content in the atmosphere and burial organic matter rates in the sedimentary rocks in Phanerozoic. The shaded zone for oxygen designates the zone of possible errors based on sensitivity analysis (Berner \& Canfield, 1989).

concentration growth) is accompanied with the enrichment of the biomass in light isotope ${ }^{12} \mathrm{C}$, while the strengthening of photorespiration (due to growth of $\mathrm{O}_{2}$ concentration) is accompanied by enrichment of the biomass with heavy isotope ${ }^{13} \mathrm{C}$. Unlike traditional photosynthesis, global photosynthesis does not have the capacity to ontogenetic changes. In addition to the features above mentioned, there are two important features of global photosynthesis, related to its participation in global carbon cycle. First is cyclicity, which is determined due to participation of global photosynthesis in orogenic cycles as their main element. Orogenic cycles, as known, are caused by the periodically recurring movement of lithospheric plates what leads to periodic injections of $\mathrm{CO} 2$ into the "atmosphere - hydrosphere" system. The combination of lithosphere plates' motion with photosynthesis development provides climatic changes. The latter causes biotic turnover. Indeed, each orogenic cycle begins with low oxygen and high $\mathrm{CO} 2$ conditions and is completed with the inverse ratio of these parameters. Drastic climatic changes cause biotic turnover. The repetition of these cycles leads to natural selection, consolidation of useful properties and adaptability of organisms in different environment. It was manifested in the structural and 
chemical features of organic matter and oils observed in the course of evolution. Actually, each photosynthetic cycle begins with low oxygen and high $\mathrm{CO}_{2}$ conditions and completing with the inverse ratio of these parameters. It resulted in drastic climatic change causing mass extinction. The repetition of these cycles leads to natural selection, consolidation of useful properties and adaptability of organisms in different environment. The second important feature of global photosynthesis is spontaneous striving to a stationary state. It is a manifestation of the ability of each individual photosynthesizing organism to enhance the photorespiration in response to the increase of oxygen content in the environment. It goes on until the amount of the evolved carbon becomes equal to the amount of the assimilated carbon. This state is called ecological compensation point. It determines the boundaries of the physical survival of the organisms. It was also shown that a set of plants, placed in the closed camera, where photosynthesis occurs, in some time make the atmosphere in the in the camera stable [4]. Tolbert et al.[5] conjectured that land plants are responsible for the equilibration of the atmosphere on the Earth. Developing this idea in respect to carbon cycle, we suggested the ecological compensation point concept. Taking into account that from the photosynthesis origin the oxygen content in the atmosphere steadily increased (Table 1) we believed that it went on up to the moment when biomass produced in photosynthesis became equal to the amount of organic matter oxidized to $\mathrm{CO}_{2}$ in the course of carbon turnover. We called this state the ecological compensation point. When the system achieved this state, all the processes in it became stationary and began to oscillate around some steady state level.

Table 1. Estimates of the average concentrations of $\mathrm{O}_{2}$ in the atmosphere during geological time, obtained by different models.

\begin{tabular}{|l|c|l|}
\hline \multicolumn{1}{|c|}{$\begin{array}{c}\text { Eon / Era } \\
\text { Namerical age } \\
\text { Ma }\end{array}$} & $\begin{array}{c}\text { Approximate } \\
\text { value }\end{array}$ & \multicolumn{1}{c|}{ References } \\
\hline $\begin{array}{l}\text { Precambrian/ Paleoproterozoic } \\
2200-2000\end{array}$ & $\sim 0,2 \%$ & $\begin{array}{l}\text { Holland 1998[7,8]; Bjerrum, } \\
\text { Canfield, 2004 [9] }\end{array}$ \\
\hline $\begin{array}{l}\text { Precambrian/ Neoproterozoic } \\
1700-570\end{array}$ & $2-3 \%$ & Canfield, Teske, 1996 [10] \\
\hline $\begin{array}{l}\text { Phanerozoic/ Cambrian- } \\
\text { Devonian }\end{array}$ & $<15-17 \%$ & $\begin{array}{l}\text { Berner, Canfield, 1989 [11]; } \\
\text { Berner et al, 2000 [12]; } \\
570-350\end{array}$ \\
\hline $\begin{array}{l}\text { Phanerozoic/ } \\
\text { Carboniferous- Permian } \\
350-230\end{array}$ & $25-30 \%$ & Lenton, 2001[14] \\
\hline $\begin{array}{l}\text { Phanerozoic/ Mezozoic Triassic- } \\
\text { Cretaceous } \\
230-145\end{array}$ & $20 \%$ & $\begin{array}{l}\text { Lenton, 2001 [14]; Bergman } \\
\text { et al., 2004 [15] }\end{array}$ \\
\hline $\begin{array}{l}\text { Phanerozoic / Cenozoic / Neogene } \\
\text { / Miocene } \\
23\end{array}$ & $23 \%$ & $\begin{array}{l}\text { Berner [16], Kothavala, 2001 } \\
{[17]}\end{array}$ \\
\hline
\end{tabular}

It was found this point was achieved in Miocene when new type of $\mathrm{CO}_{2}$ assimilation, called C4-type, has appeared [6]. Since this moments the regulation of the $\mathrm{CO}_{2} / \mathrm{O}_{2}$ ratio and the associated processes turned to be under the control and began to realize through the change in the ratio of $\mathrm{C} 3 / \mathrm{C} 4$ type plants. The last feature of global photosynthesis has a very deep physical sense. Indeed, when the system became steady state it has become very unstable and dependent even on weak external impacts. Simultaneously many important vital parameters of the system, such as $\mathrm{O}_{2}$ and $\mathrm{CO}_{2}$ concentrations, surface temperatures, sea level, etc., which critical to humanity existence, has become unstable too. It makes people to follow closely variations of parameters to counter threats. From the stationary state of the global carbon cycle one can deduced that the amount of carbon produced in photosynthesis is approximately constant. Hence the amount of hydrocarbons produced by organic matter should be approximately constant too, as well as the amount of generated petroleum. Considering the steady state of oil reproduction and the ever increasing volume of its consumption, the expression that oil is a non-renewable resource acquires obvious sense.

\section{Conclusion}

1. The term "global photosynthesis" is necessary to describe photosynthesis in large systems such as the biosphere or the global carbon cycle. On the basis of the equation of traditional photosynthesis, approximations were obtained that describe the "substrate - product" and "product - product" relationships in photosynthesis for the large systems, like biosphere and global carbon cycle.

2. It is shown that to study the changes occurred during the evolution of the global carbon cycle, in particular, for the identification of orogenic cycles, it is possible to use such features of traditional photosynthesis as the dependence of photosynthesis products on environmental conditions, as features of carbon isotope fractionation and others features, excepting ontogenetic ones

3. The features of global photosynthesis associated with participation in the global carbon cycle, such as cyclicality and spontaneous striving to a stationary state with oxygen growth in the environment, are of special interest. The first is responsible for natural selection and fixation of useful properties in the course of evolution, including the ability to adaptation, A spontaneous approach of the system to a stationary state, called ecological compensation point, means that eventually the system will reach it. This state is very unstable and is sensitive to weak external impacts. Therefore, such vital parameters of the system, as the oxygen and carbon dioxide content in the atmosphere, the associated surface temperature on the Earth, sea level and many others are unstable as well and should be monitored. That's why the numerous environmental problems inevitably arise and humanity needs to solve them to survive.

4. Following the logic of stationary state one can conclude that in position of ecological compensation point the reproduction of sedimentary organic matter becomes steady state as well. Given that oil generation makes up a certain portion of sedimentary organic matter and taking into account that oil consumption is steadily increases it become evident that it is high time to think what should replace the oil disappearing.

\section{References}

1. Vernadsky VI (1926) Isotopes and "living" matter. Dokl.

2. Ivlev AA (2019) The Global Carbon Cycle and the Evolution of photosynthesis. Cambridge Scholars Publishing. 
3. Ivlev AA (2019) Functions of Global Photosynthesis. AS Agriculture 3: 23-24.

4. Jahren $\mathrm{AH}$, Arens NC, Harbeson SA (2008) Prediction of atmospheric $\delta^{13} \mathrm{CO}_{2}$ using fossil plant tissues. Rev Geophys 46.

5. Tolbert NE, Benker C, Beck E (1995) The oxygen and carbon dioxide compensation points of $\mathrm{C}_{3}$ plants: Possible role in regulating atmospheric oxygen. Proc Natl Acad Sci 92: 11230-11233. (Crossref)

6. Cerling TE, Harris JM, MacFadden BJ, Leakey MJ, Quade J, et al. (1997) Global vegetation change through Miocene/Pliocene boundry. Nature 389: 153-158.

7. Holland HD (1965) The history of ocean water and its effect on the chemistry of atmosphere. Proc Natl Acad Sci USA 53: 1173-1183. (Crossref)

8. Igamberdiev AU, Lea PJ (2006) Land plants equilibrate $\mathrm{O}_{2}$ and $\mathrm{CO}_{2}$ concentrations in the atmosphere. Photosynthesis research 87: 177-194. (Crossref)

9. Bjerrum CJ, Canifield DE (2004) New insight into the burial history of organic carbon on the early Earth. Geochim Geophys Geosyst 5.

10. Canfield DE, Teske A (1996) Late Proterozoic rise in atmospheric oxygen inferred from phylogenetic and sulphur-isotope studies. Nature 382: 127-132. (Crossref)
11. Berner RA, Canfield DE (1989) A new model for atmospheric oxygen over Phanerozoic time. Am J Sci 289: 333-361. (Crossref)

12. Berner RA, Petsch ST, Lake JA, Beerling DJ, Popp BN et al. (2000) Isotope fractionation and atmospheric oxygen: implications for Phanerozoic $\mathrm{O}_{2}$ evolution. Science 287: 1630-1633.

13. Berner R (2003) The long-term carbon cycle, fossil fuels and atmospheric composition. Nature 426: 323-326. (Crossref)

14. Lenton TM (2001) The role of land plants, phosphorous weathering and fire in the rise and regulation of atmospheric oxygen. Global Change Biol 7: 613-629.

15. Bergman MJ, Lenton TM, Watson (2004) AG COPSE: a new model of biogeochemical cycling over Phanerozoic time. Am J Sci 304: 397-437.

16. Berner RA (1999) Atmospheric oxygen over Phanerozoic time. Proc Natl Acad Sci USA 96: 10955-10957. (Crossref)

17. Berner RA, Kothavala Z (2001) GEOCARB III: a revised model of atmospheric $\mathrm{CO}_{2}$ over Phanerozoic time Am J Sci 301: 333-361.

\section{Citation:}

Ivlev AA (2020) Global Photosynthesis is an Instrument in large Natural Systems Studies. Geol Earth Mar Sci Volume 1(1): 1-4. 